\title{
Produção de mudas de maracujá amarelo com diferentes materiais refletores sobre bancada
}

\author{
Tiago Vilela Santos ${ }^{1}$, Thamíris Campaneli Lopes ${ }^{1}$, Abimael Gomes Silva ${ }^{1}$, Rita de Cássia \\ Mariano de Paula ${ }^{1}$, Edilson Costa ${ }^{1}$, Flávio Ferreira da Silva Binotti ${ }^{1}$ \\ ${ }^{1}$ Universidade Estadual de Mato Grosso do Sul, Unidade de Cassilândia, Cassilândia, MS, Brasil. E-mail: tiago-vilela@ hotmail.com, \\ thamiris-campaneli@hotmail.com, maeldruida@hotmail.com,rcmp92@hotmail.com, mestrine@uems.br, binotti@uems.br
}

Recebido: 20/06/2017; Aceito: 05/09/2017.

\section{RESUMO}

O maracujá amarelo (Passiflora edulis Sims. f. flavicarpa Deg) é uma das espécies frutíferas mais cultivadas no Brasil, mais vigorosa e mais adaptada aos dias quentes. Objetivou-se avaliar a utilização de diferentes materiais refletores em bancadas de cultivo, visando melhor aproveitamento da luz no interior do ambiente protegido, para obtenção de mudas de maracujazeiro vigorosas e de elevada qualidade. O experimento foi conduzido em delineamento inteiramente casualizado, com 5 tratamentos e 6 repetições. Foram testados os seguintes tratamentos: T1: testemunha (bancada metálica de cor cinza, sem material refletor); T2: bancada metálica coberta com papel alumínio; T3: bancada metálica coberta com tecido "falso paetê"; T4: bancada metálica coberta com espelho; T5: bancada metálica coberta com bandeja de papel laminada. Foram avaliados o índice de velocidade de emergência, altura média de plantas, número de folhas, teor de clorofila na folha, matéria seca da parte aérea, matéria seca da raiz, matéria seca total, taxa de crescimento relativo e taxa de crescimento absoluto. Dentre as radiações refletidas pelos materiais de cobertura da bancada, o espelho apresentou a maior média. Mudas produzidas sobre o espelho apresentaram maior taxa de crescimento, matéria seca da parte aérea quando comparadas com as produzidas sobre o tecido. No final das avaliações foi observado maior acúmulo de clorofila nas mudas que utilizaram o espelho como material refletor. O uso do tecido como material refletor não é recomendado.

Palavras-chave: Passiflora edulis Sims. f. flavicarpa Deg, ambiente protegido, espelho.

\section{Production of yellow passion seedlings with different reflectors materials on bench}

\begin{abstract}
The yellow passion fruit (Passiflora edulis Sims, f. flavicarpa Deg) is one of the most cultivated fruit species in Brazil, more vigorous and more adapted to hot days. The objective of this study was to evaluate the use of different reflective materials in cultivation stands, aiming at better use of light within the protected environment, in order to obtain vigorous and high quality yellow passion seedlings. The experiment was conducted in a completely randomized design with 5 treatments and 6 replicates. The following treatments were tested: T1: control (gray metal bench, without reflective material); T2: metal bench covered with aluminum foil; T3: metal bench covered with fabric "false paete"; T4: metal bench covered with mirror; T5: metal bench covered with laminated paper tray. The emergence speed index, plant height, leaf number, leaf chlorophyll content, shoot dry matter, root dry matter, total dry matter, relative growth rate and absolute growth rate were evaluated. Among the radiations reflected by the covering materials of the bench, the mirror presented the highest average. Seedlings produced on the mirror had a higher growth rate, shoot dry matter when compared to those produced on the fabric. At the end of the evaluations, greater accumulation of chlorophyll was observed in the seedlings that used the mirror as a reflecting material. The use of the fabric as a reflective material is not recommended.
\end{abstract}

Key words: Passiflora edulis Sims. f. flavicarpa Deg, protected environment, mirror. 


\section{Introdução}

A fruticultura brasileira está em franca expansão, assistindo pequenos e grandes produtores que utilizam alta tecnologia (COSTA et al., 2010a). O gênero Passiflora possui mais de 400 espécies sendo que cerca de 200 delas são nativas do Brasil (BARROS et al., 2013).

O maracujazeiro-amarelo (Passiflora edulis Sims. $f$. flavicarpa Deg), é uma planta de aspecto herbáceo, provida de gavinhas e hábito trepador (COSTA et al., 2011). Além disso, tem sua distribuição notadamente localizada em tropical nas Américas e na África, pertencendo à família Passifloraceae. A maior parte da produção brasileira de maracujá é da variedade amarelo ou azedo, que tem grande aproveitamento industrial e grande parte da fruta é destinada para a fabricação de suco (MELETTI, 2011).

De acordo com o IBGE (2013), a produtividade média anual dessa fruta no Brasil foi de $14,63 \mathrm{Mg} \mathrm{ha}^{-1}$; $74 \%$ da produção está concentrada na região nordeste devido à sua adaptação edafoclimática e pela preferência e aceitação de seus frutos para o consumo in natura. De acordo com Sá et al. (2014), devido a essa aceitação houve um crescimento na produção, intensificando o agronegócio da cultura e colaborando para o desenvolvimento econômico do país. Como efeito da expressão da cultura do maracujá, nota-se um maior interesse dos produtores no aumento dos pomares.

A muda vigorosa é imprescindível para formação de um pomar e para a obtenção de uniformidade, aumentando a produtividade e principalmente a precocidade da primeira produção (PRADO et al., 2005). Costa et al. (2009) sugerem que as mudas utilizadas sejam de alta qualidade e com baixo custo de produção, pois, além de ser um componente importante do investimento na fruticultura, por ser um pré-requisito fundamental ao sucesso da atividade, é também um dos mais expressivos itens, especialmente nos empreendimentos que tendem a atingir as parcelas mais nobres do mercado consumidor.

Dentre os vários elementos micrometeorológicos no ambiente de cultivo, o principal para o crescimento das plantas é a luz, que não apenas fornece energia luminosa para a fotossíntese, mas também fornece sinais que regulam o seu desenvolvimento por meio de receptores, deste modo, uma espécie está adaptada a modificações nos níveis de luminosidade quando pode propiciar respostas fisiológicas diferentes nas suas características anatômicas, bioquímicas e de crescimento (ZANELLA et al., 2006). Os fatores que afetam a atividade fotossintética dos vegetais são principalmente a intensidade luminosa, concentração de $\mathrm{CO}_{2}$, teor de nitrogênio da folha, temperatura e umidade do solo, desta forma a capacidade fotossintética de cada espécie vegetal se torna uma característica própria (COSTA; MARENCO, 2007).

A ambiência vegetal é o conjunto de elementos que compõe as condições micrometeorológicas da área/espaço de produção, visando obter as melhores condições para o desenvolvimento das plantas e melhor produtividade. Dessa forma, é importante o conhecimento da produção de mudas em ambientes protegidos, como estufas agrícolas, viveiros telados, casas de vegetação climatizadas, entre outras técnicas que permitem melhor utilização dos elementos micrometeorológicos.

Estudos com a ambiência vegetal na formação de mudas de maracujazeiro foram realizados comparando diferentes configurações e coberturas de ambientes protegidos (MENDONÇA et al., 2005; ZANELLA et al., 2006; COSTA et al., 2009; COSTA et al., 2010a; COSTA et al., 2010b; COSTA et al., 2011). Zanella et al. (2006) testando níveis de sombreamento $(0 \%$; 30\%; $50 \%$ e $80 \%$ ) com tela preta, na formação de mudas de maracujazeiro, verificaram que a exposição a pleno sol foi prejudicial às mudas e os níveis de sombreamento de $50 \%$ e $80 \%$ foram os mais favoráveis ao crescimento. Estudos sobre ambiência vegetal com o uso de material refletor em bancadas de cultivo, visando o melhor aproveitamento da luz no interior do ambiente protegido não foram encontrados em literatura.

Portanto, objetivou-se avaliar a utilização de diferentes materiais refletores em bancadas de cultivo, visando melhor aproveitamento da luz no interior do ambiente protegido, para obtenção de mudas de maracujazeiro vigorosas e de elevada qualidade.

\section{Material e Métodos}

$\mathrm{O}$ experimento foi realizado em área experimental da Universidade Estadual de Mato Grosso do Sul (UEMS), na Unidade Universitária de Cassilândia, no período de 27 de outubro de 2015 a 6 de janeiro de 2016. A região está localizada em altitude de $516 \mathrm{~m}$, longitude de 51\%44'W e latitude de 1906' S" (Estação automática CASSILANDIA-A742). O clima dessa região, de acordo com Köeppen, é tropical com estação seca $(\mathrm{Aw})$.

$\mathrm{O}$ experimento foi instalado sob telado agrícola, de estrutura em aço galvanizado, possuindo $8,0 \mathrm{~m}$ de largura por 18,0 m de comprimento, com altura de 4,0 $\mathrm{m}$, coberto com tela aluminizada termorrefletora de $50 \%$ de sombreamento a $3,30 \mathrm{~m}$, e fechamentos laterais em ângulo de $90^{\circ}$ graus com tela preta de $50 \%$ de sombreamento.

Foram testados materiais refletores em bancadas de cultivo no interior do ambiente protegido. $\mathrm{O}$ experimento foi conduzido num delineamento inteiramente casualizado, com 5 tratamentos, 6 
repetições de 3 mudas cada. As mudas foram dispostas em fileiras com espaçamento de $12 \mathrm{~cm}$. Os tratamentos foram compostos por materiais refletores dispostos em bancadas de cultivo, em que: T1: testemunha, bancada metálica de cor cinza sem material refletor; T2: bancada metálica coberta com papel alumínio; T3: bancada metálica coberta com tecido chamado "falso paetê"; T4: bancada metálica coberta com espelho; T5: bancada metálica coberta com bandeja de papel laminado. Cada material refletor cobriu uma área de 1,0 m x 1,2 m.

Para a produção das mudas de maracujazeiro (Passiflora edulis Sims f. flavicarpa Deg.) foram utilizados sacos plásticos de 1,8 litros, contendo substrato composto por $30 \%$ de esterco $+30 \%$ de solo + $40 \%$ de areia (Tabelas 1 e 2).

Os sacos plásticos foram dispostos em bancadas de $1,40 \mathrm{~m}$ de largura por $3,50 \mathrm{~m}$ de comprimento e altura de $1,0 \mathrm{~m}$ do solo. Foram semeadas duas sementes por saco plástico, observando-se emergência aos 10 dias após a semeadura (DAS). Após formação de três folhas definitivas foi realizado o desbaste (com auxilio de uma tesoura) aos 20 DAS, permanecendo assim a muda mais vigorosa. A irrigação das mudas ocorreu duas vezes ao dia, no período da manhã e no período da tarde, quando necessário.

Os dados da emergência foram coletados diariamente até sua estabilização. Posteriormente, determinou-se o índice de velocidade de emergência (IVE) adaptado da metodologia proposta por Maguire (1962). Foi mensurada a altura das plantas (AP), número de folhas (NF) e estimativa do teor de clorofila pelo índice SPAD (CL ou índice relativo do teor de clorofila) que foram coletados aos $30\left(\mathrm{AP}_{1}, \mathrm{NF}_{1}, \mathrm{CL}_{1}\right)$, $50\left(\mathrm{AP}_{2}, \mathrm{NF}_{2}, \mathrm{CL}_{2}\right)$ e $70\left(\mathrm{AP}_{3}, \mathrm{NF}_{3}, \mathrm{CL}_{3}\right)$ DAS. Aos 70 DAS foram coletadas também a matéria seca da parte aérea (MSPA), matéria seca da raiz (MSR) e matéria seca da parte total, sendo estes valores dados em $\mathrm{g} /$ planta. Foram determinadas as taxas de crescimento absoluto e relativo (TCA, TCR) dos 30 aos 50 (DAS), $\left(\mathrm{TCA}_{1}, \mathrm{TCR}_{1}\right)$, dos 50 aos 70 (DAS), $\left(\mathrm{TCA}_{2}, \mathrm{TCR}_{2}\right) \mathrm{e}$ dos 30 aos 70 (DAS) $\left(\mathrm{TCA}_{3}, \mathrm{TCR}_{3}\right.$ ) (BENINCASA, 1988).

A altura da muda (AP) foi obtida por meio de régua milimetrada medindo do coleto até a gema apical. O teor de clorofila foi obtido pelo índice SPAD (TC ou índice relativo do teor de clorofila) por meio de clorofilômetro digital. A massa da matéria seca da parte aérea (MSPA) e a massa da matéria seca do sistema radicular (MSR) foram secas em estufa com circulação de ar forçada, à temperatura de $65^{\circ} \mathrm{C}$ até atingir massas constantes, e mensuradas em balança analítica. Foram coletadas, às 10 horas da manhã, em dias de céu limpo, a radiação fotossinteticamente ativa refletida $\left(\mu \mathrm{mol} \mathrm{m}{ }^{-2}\right.$ $\mathrm{s}^{-1}$ ) de cada material (tratamento), a radiação fotossinteticamente ativa incidente $\left(\mu \mathrm{mol} \mathrm{m} \mathrm{m}^{-2} \mathrm{~s}^{-1}\right)$ no interior e exterior ao ambiente protegido, sendo mensuradas com equipamento da marca Apogee modelo MP-200 (Figuras 1 e 2).

$\mathrm{Na}$ Tabela 3 estão especificadas as médias das radiações fotossinteticamente ativa no exterior e interior do ambiente protegido, bem como as radiações refletidas nos diversos materiais de cobertura da bancada de cultivo. A partir da média da radiação interna foi determinada a porcentagem de radiação fotossinteticamente ativa dos materiais utilizados.

Os dados foram submetidos à análise de variância (teste F) e as médias comparadas pelo teste de Tukey a $5 \%$ de probabilidade, com o software Sisvar 5.3 (FERREIRA, 2010).

Tabela 1. Resultado da análise das características do esterco utilizado. Cassilândia-MS, 2015.

\begin{tabular}{|c|c|c|c|c|c|c|c|}
\hline $\mathrm{N}$ & $\mathrm{P}_{2} \mathrm{O}_{5}$ & $\mathrm{~K}_{2} \mathrm{O}$ & $\mathrm{Ca}$ & $\mathrm{Mg}$ & $\mathrm{S}$ & $\mathrm{U}-65^{\circ} \mathrm{C}$ & $\mathrm{C}$ \\
\hline \multicolumn{8}{|c|}{ 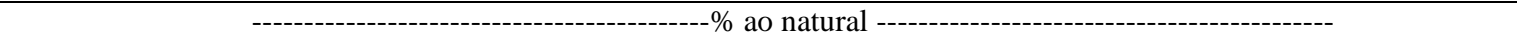 } \\
\hline 0,9 & 0,3 & 0,1 & 0,3 & 0,1 & 0,2 & 2,0 & 11,0 \\
\hline $\mathrm{Na}$ & $\mathrm{Cu}$ & $\mathrm{Fe}$ & $\mathrm{Mn}$ & $\mathrm{Zn}$ & $\mathrm{C} / \mathrm{N}$ & $\mathrm{pH}$ & MO \\
\hline \multicolumn{6}{|c|}{----------------mg kg ${ }^{-1}$ ao natural ----------- } & $\mathrm{CaCl}_{2}$ & $\%$ ao natural \\
\hline 624 & 18 & 12103 & 204 & 53 & $12 / 1$ & 5,3 & 20,0 \\
\hline
\end{tabular}

$\mathrm{U}=$ umidade; $\mathrm{MO}$ = matéria orgânica; $\mathrm{C} / \mathrm{N}$ = relação carbono e nitrogênio.

Tabela 2. Resultado da análise das características do solo de barranco utilizado. Cassilândia-MS, 2015.

\begin{tabular}{|c|c|c|c|c|c|c|}
\hline $\begin{array}{c}P_{\text {resina }} \\
\mathrm{mg} \mathrm{dm}^{-3}\end{array}$ & K & $\mathrm{Ca}$ & $\mathrm{Mg}$ & SB & CTC & V\% \\
\hline 4 & 0,6 & 7 & 3 & 11 & 50 & 22 \\
\hline $\mathrm{pH}$ & $\mathrm{MO}$ & B & $\mathrm{Cu}$ & $\mathrm{Fe}$ & $\mathrm{Mn}$ & $\mathrm{Zn}$ \\
\hline $\begin{array}{c}\text { Agua } \\
4,6\end{array}$ & $\begin{array}{c}\mathrm{g} \mathrm{dm}^{-3} \\
6\end{array}$ & 0,21 & 0,5 & 15 & 8,3 & 0,1 \\
\hline
\end{tabular}

$\mathrm{MO}=$ matéria orgânica. 


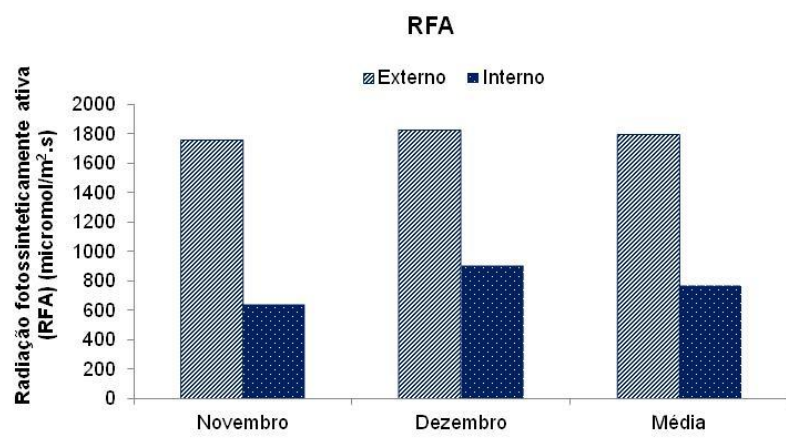

Figura 1. Radiação fotossinteticamente ativa (RFA) no exterior e no interior do ambiente protegido. Cassilândia, MS, 2016.

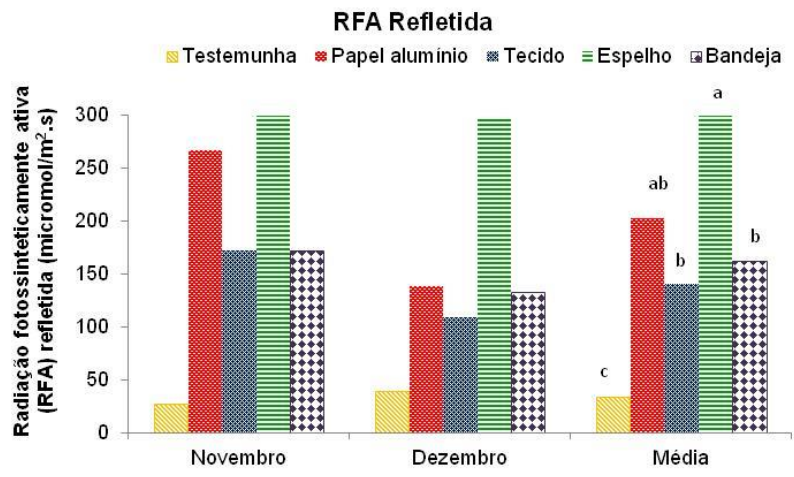

Figura 2. Radiação fotossinteticamente ativa refletida (RFA) nos diversos materiais de cobertura da bancada de cultivo. Médias seguidas por letras iguais não diferem entre si pelo teste de Tukey, a 5\% de probabilidade. Cassilândia, MS, 2016.

\section{Resultados e Discussão}

No início do experimento, as condições físicas de refletância dos materiais testados não influenciaram o índice de velocidade de emergência do maracujazeiro (Tabela 4), apesar dos materiais apresentarem diferentes resultados de radiação fotossinteticamente ativa refletida (Figura 2, Tabela 3).

Nos primeiros dias da emergência as mudas não possuem folhas verdadeiras e capacidade fotossintética, sendo assim, os principais fatores que influenciam nesta etapa são a temperatura, oxigênio e umidade (MARCOS FILHO, 2015). Os diferentes materiais testados não interferiram nestes fatores e não propiciaram modificações para auxiliar a emergência das plântulas.

A altura não foi influenciada pelos materiais refletores aos 30 DAS, no entanto, aos 50 DAS as mudas da testemunha e do espelho estavam maiores que as produzidas na bancada com tecido refletor falso paetê. Aos 70 DAS as mudas produzidas sobre o espelho estavam maiores que as produzidas nos demais tratamentos, revelando influência deste material no crescimento vegetal (Tabela 5), pois a maior refletância deste material (Figura 2; Tabela 3) propiciou melhores condições para a fotossíntese e consequentemente maior capacidade de crescimento da muda.

Para números de folhas, na avaliação de 30 DAS, as mudas da testemunha se diferiram das produzidas sobre o tecido. Aos 50 DAS o tratamento com o espelho proporcionou maior resultado quando comparado com o tratamento que utilizou o tecido como material refletor, sendo que aos 70 (DAS) os tratamentos não se diferiram entre si (Tabela 5).

Tabela 4. Índice de velocidade de emergência de plantas (IVE). Cassilândia-MS, 2016.

\begin{tabular}{lc}
\hline Tratamentos & $\begin{array}{c}\text { Índice de velocidade de } \\
\text { emergência }\end{array}$ \\
\hline Testemunha & $0,364 \mathrm{a}$ \\
Papel alumínio & $0,334 \mathrm{a}$ \\
Tecido & $0,317 \mathrm{a}$ \\
Espelho & $0,347 \mathrm{a}$ \\
Bandeja & $0,454 \mathrm{a}$ \\
\hline CV $(\%)$ & 27,10
\end{tabular}

Médias seguidas por letras iguais na coluna não diferem entre si pelo teste de Tukey, a 5\% de probabilidade.

Tabela 5. Altura da planta e número de folhas do maracujazeiro amarelo aos 30,50 e 70 dias após a semeadura (DAS). Cassilândia-MS, 2016.

\begin{tabular}{lccc}
\hline \multirow{2}{*}{ Tratamentos } & \multicolumn{3}{c}{ Altura de planta $(\mathrm{cm})$} \\
\cline { 2 - 4 } & 30 DAS & 50 DAS & 70 DAS \\
\hline Testemunha & $3,47 \mathrm{a}$ & $12,40 \mathrm{a}$ & $22,66 \mathrm{~b}$ \\
Papel alumínio & $2,93 \mathrm{a}$ & $8,88 \mathrm{ab}$ & $21,46 \mathrm{~b}$ \\
Tecido & $2,23 \mathrm{a}$ & $6,08 \mathrm{~b}$ & $10,16 \mathrm{~b}$ \\
Espelho & $3,41 \mathrm{a}$ & $13,50 \mathrm{a}$ & $36,75 \mathrm{a}$ \\
Bandeja & $3,03 \mathrm{a}$ & $9,16 \mathrm{ab}$ & $22,04 \mathrm{~b}$ \\
\hline CV\% & 24,43 & 23,44 & 27,32 \\
\hline \multirow{2}{*}{ Tratamentos } & \multicolumn{3}{c}{ Número de folhas } \\
\cline { 2 - 4 } & 30 DAS & 50 DAS & 70 DAS \\
\hline Testemunha & $5,66 \mathrm{a}$ & $9,67 \mathrm{ab}$ & $11,58 \mathrm{a}$ \\
Papel alumínio & $4,58 \mathrm{ab}$ & $8,75 \mathrm{ab}$ & $11,25 \mathrm{a}$ \\
Tecido & $3,58 \mathrm{~b}$ & $6,58 \mathrm{~b}$ & $7,67 \mathrm{a}$ \\
Espelho & $5,08 \mathrm{ab}$ & $11,08 \mathrm{a}$ & $11,75 \mathrm{a}$ \\
Bandeja & $4,75 \mathrm{ab}$ & $9,83 \mathrm{ab}$ & $11,25 \mathrm{a}$ \\
\hline CV\% & 18,10 & 17,36 & 21,93 \\
\hline
\end{tabular}

Médias seguidas por letras iguais na coluna não diferem entre si pelo teste de Tukey, a 5\% de probabilidade.

Tabela 3. Média das radiações fotossinteticamente ativa no exterior e interior do ambiente protegido e das radiações refletidas nos diversos materiais de cobertura da bancada de cultivo no período de 29/10 a 31/12/2015. Cassilândia-MS, 2016.

\begin{tabular}{|c|c|c|c|c|c|c|c|}
\hline & \multicolumn{7}{|c|}{ Radiação fotossinteticamente ativa $\left(\mu \mathrm{omol} \mathrm{m} \mathrm{s}^{-2} \mathrm{~s}^{-1}\right)$} \\
\hline & EX & IN & $\mathrm{TEr}$ & Par & $\mathrm{TCr}$ & $\mathrm{ESr}$ & $\mathrm{BPr}$ \\
\hline Média & 1788,9 & 765,8 & 33,6 & 203,6 & 140,8 & 335,6 & 162,1 \\
\hline Porcentagem & & 100 & 4,4 & 26,6 & 18,4 & 43,8 & 21,2 \\
\hline
\end{tabular}


Na clorofila avaliada aos 30 DAS, as mudas do tratamento com a bandeja apresentaram maior resultado quando comparado com o tecido, já com 50 DAS os tratamentos não apresentaram diferença entre si. Aos 70 DAS as mudas provenientes do espelho apresentaram maiores valores quando comparados àquelas sobre $\mathrm{o}$ tecido (Tabela 6).

$\mathrm{O}$ índice SPAD é utilizado para o diagnóstico do estado de nitrogênio das culturas, elemento relacionado à produtividade vegetal (PORTO et al., 2014). De acordo com Morgado et al. (2011), em ensaio com o maracujazeiro amarelo, esse índice é um método indireto de mensurar a concentração de clorofila nessa espécie. Portanto o tecido apresentou o pior desempenho em refletir a RFA, o que resultou em plantas com menor concentração de clorofila.

$\mathrm{O}$ espelho e a bandeja resultaram em mudas com maiores valores de matéria seca da parte aérea se comparado ao tecido. Quanto à matéria seca da raiz a testemunha, espelho, papel alumínio e a bandeja resultaram em mudas com maiores médias diferindo do tratamento com tecido. $\mathrm{O}$ espelho resultou em mudas com maiores massa seca total quando comparado com o tecido (Tabela 6).

Para taxa de crescimento relativo (TCR) o espelho promoveu maior resultado em relação ao tecido, após 50 DAS (Tabela 7). A TCR é considerada um índice de eficiência por representar a capacidade vegetal em produzir biomassa. Os valores iniciais para essa taxa são sempre superiores aos finais sendo explicado pelo crescimento de estruturas que não contribuem para o processo fotossintético e o auto-sombreamento das folhas no decorrer do crescimento vegetal (FEY et al., 2010). De acordo com Conforto et al. (2011) o sombreamento interfere no aproveitamento da radiação solar culminando em prejuízos no desenvolvimento. No presente estudo a utilização do material refletor faz com que a planta aumente sua taxa fotossintética, pois a RFA é refletida para as folhas da parte inferior (abaxial) e a planta obtém maior quantidade de energia para o crescimento.

O espelho produziu uma taxa de crescimento absoluto (TCA) maior dos 30-70 DAS (Tabela 7). A TCA indica o incremento de biomassa seca e seu valor elevado pode indicar qualidade. De acordo com Dias et al. (2013), maracujazeiros com TCA menores foram obtidos com incremento de salinidade no substrato através da irrigação. Pelos tratamentos testados esse incremento de biomassa e qualidade da muda foi verificado com o uso de espelho na bancada.

Ao comparar os resultados de todas as variáveis é possível perceber que o tecido resultou no maior número de variáveis com menores valores. Em contrapartida, dentre os materiais avaliados, o espelho se mostrou o material mais eficiente para refletir a radiação fotossinteticamente ativa. Nos valores de massa seca total, da parte aérea e radicular, assim como nas análises de taxa de crescimento, o uso do espelho gerou maiores resultados, o que evidencia que esta radiação foi melhor aproveitada pelo aparato fotossintético vegetal contribuindo para o acúmulo de reservas e maior fitomassa e consequente crescimento e desenvolvimento vegetal.

Tabela 6. Clorofila de plantas de maracujazeiro amarelo aos 30,50 e 70 dias após a semeadura (DAS) e matéria seca da parte aérea (MSPA), matéria seca da raiz (MSR) e matéria seca total (MST) aos 70 DAS. Cassilândia-MS, 2016.

\begin{tabular}{lccc}
\hline \multirow{2}{*}{ Tratamentos } & \multicolumn{3}{c}{ Clorofila (SPAD) } \\
\cline { 2 - 4 } Testemunha & $11,87 \mathrm{ab}$ & $21,08 \mathrm{a}$ & $18,76 \mathrm{ab}$ \\
Papel alumínio & $11,67 \mathrm{ab}$ & $19,24 \mathrm{a}$ & $17,21 \mathrm{ab}$ \\
Tecido & $6,94 \mathrm{~b}$ & $11,40 \mathrm{a}$ & $11,21 \mathrm{~b}$ \\
Espelho & $13,30 \mathrm{ab}$ & $22,28 \mathrm{a}$ & $24,02 \mathrm{a}$ \\
Bandeja & $15,86 \mathrm{a}$ & $22,02 \mathrm{a}$ & $20,71 \mathrm{ab}$ \\
\hline CV\% & 33,63 & 29,21 & 27,83 \\
\hline Tratamentos & Matéria seca da parte aérea, da raiz e total \\
\hline \multicolumn{4}{c}{ aos 70 DAS } \\
\hline Testemunha & $3,123 \mathrm{ab}$ & $1,173 \mathrm{a}$ & $4,297 \mathrm{a}$ \\
Papel alumínio & $3,118 \mathrm{ab}$ & $1,025 \mathrm{a}$ & $4,143 \mathrm{ab}$ \\
Tecido & $1,245 \mathrm{~b}$ & $0,503 \mathrm{~b}$ & $1,748 \mathrm{~b}$ \\
Espelho & $5,115 \mathrm{a}$ & $1,300 \mathrm{a}$ & $6,415 \mathrm{a}$ \\
Bandeja & $4,328 \mathrm{a}$ & $1,195 \mathrm{a}$ & $5,523 \mathrm{a}$ \\
\hline CV\% & 28,21 & 17,57 & 24,85 \\
\hline
\end{tabular}

Médias seguidas por letras iguais na coluna não diferem entre si pelo teste de Tukey, a $5 \%$ de probabilidade.

Tabela 7. Taxa de crescimento relativo (TCR) e taxa de crescimento absoluto (TCA) do maracujazeiro amarelo dos 30-50 (DAS), 50-70 DAS e 30-70 (DAS). Cassilândia, MS, 2016.

\begin{tabular}{lccc}
\hline & \multicolumn{3}{c}{ Taxa de crescimento relativo (g/dia) } \\
\hline Tratamentos & $30-50 \mathrm{DAS}$ & $50-70 \mathrm{DAS}$ & $30-70 \mathrm{DAS}$ \\
\hline Testemunha & $0,064 \mathrm{a}$ & $0,026 \mathrm{ab}$ & $0,044 \mathrm{ab}$ \\
Papel alumínio & $0,055 \mathrm{a}$ & $0,038 \mathrm{ab}$ & $0,046 \mathrm{ab}$ \\
Tecido & $0,055 \mathrm{a}$ & $0,022 \mathrm{~b}$ & $0,038 \mathrm{~b}$ \\
Espelho & $0,068 \mathrm{a}$ & $0,044 \mathrm{a}$ & $0,055 \mathrm{a}$ \\
Bandeja & $0,056 \mathrm{a}$ & $0,037 \mathrm{ab}$ & $0,046 \mathrm{ab}$ \\
\hline CV\% & 13,08 & 26,34 & 12,84 \\
\hline & Taxa de crescimento absoluto $(\mathrm{g} /$ dia) \\
\hline Tratamentos & $30-50 \mathrm{DAS}$ & $50-70 \mathrm{DAS}$ & $30-70 \mathrm{DAS}$ \\
\hline Testemunha & $0,45 \mathrm{ab}$ & $0,45 \mathrm{~b}$ & $0,45 \mathrm{~b}$ \\
Papel alumínio & $0,30 \mathrm{bc}$ & $0,55 \mathrm{ab}$ & $0,43 \mathrm{~b}$ \\
Tecido & $0,20 \mathrm{c}$ & $0,18 \mathrm{~b}$ & $0,18 \mathrm{~b}$ \\
Espelho & $0,51 \mathrm{a}$ & $1,01 \mathrm{a}$ & $0,78 \mathrm{a}$ \\
Bandeja & $0,31 \mathrm{bc}$ & $0,56 \mathrm{ab}$ & $0,44 \mathrm{~b}$ \\
\hline CV\% & 25,04 & 40,43 & 29,94 \\
\hline
\end{tabular}

Médias seguidas por letras iguais na coluna não diferem entre si pelo teste de Tukey, a $5 \%$ de probabilidade. 


\section{Conclusões}

O espelho, como material refletor, proporcionou mudas de maracujazeiro amarelo com qualidade elevada.

Não é recomendado o uso do tecido "falso paetê" como material refletor.

\section{Agradecimentos}

À Fundação de Apoio ao Desenvolvimento do Ensino, Ciência e Tecnologia do Estado de Mato Grosso do Sul (FUNDECT);

À Coordenação de Aperfeiçoamento de Pessoal de Nível Superior (CAPES) pelo apoio financeiro e pela concessão de bolsas.

Ao Programa de Apoio a Núcleos Emergentes (PRONEM/FUNDECT/CNPq N N $^{\circ}$ 15/2014; Termo de Outorga 080/2015, SIAFEM: 024367;

Ao Programa Primeiros Projetos (PPP/FUNDECT $\mathrm{N}^{\circ}$ 05/2011, Termo de Outorga: 0152/12 SIAFEM: 020865 .

\section{Referências Bibliográficas}

BARROS, C. M. B.; MÜLLER, M. M. L.; BOTELHO, R. V.; MICHALOVICZ, L.; VICENSI, M.; NASCIMENTO, R. Substratos com compostos de adubos verdes e biofertilizante via foliar na formação de mudas de maracujazeiro-amarelo. Semina: Ciências Agrárias, Londrina-PR, v. 34, n. 6, p. 2575-2588, 2013

BENINCASA, M. M. P. Análise de crescimento de plantas: noções básicas. Jaboticabal-SP: FUNEP, 1988. 42p.

CONFORTO, E. C.; BITTENCOURT JÚNIOR, N. S.; SCALOPPI JÚNIOR, E. J.; MORENO, R. M. Comparação entre folhas sombreadas de sete clones adultos de seringueira. Revista Ceres, Viçosa, MG, v. 58, n. 1, p. 29-34, 2011.

COSTA, E.; LEAL, P. A. M.; SANTOS, L. C. R.; VIEIRA, L. C. R. Ambientes de cultivo, recipientes e substratos na produção de biomassa foliar e radicular em mudas de maracujazeiro amarelo em Aquidauana - MS. Ciência e Agrotecnologia, Lavras-MG, v. 34, n. 2, p. 461-467, 2010 b.

COSTA, E.; LEAL, P. A. M.; SASSAQUI, A. R.; GOMES, V. A. Doses de composto orgânico comercial na composição de substratos para a produção de mudas de maracujazeiro em diferentes tipos de cultivo protegido. Engenharia Agrícola, Jaboticabal-SP, v. 30, n. 5, p. 776-787, 2010a.

COSTA, E.; RODRIGUES, E. T.; ALVES, V. B.; SANTOS, L. C. R.; VIEIRA, L. C. R. Efeitos da ambiência, recipientes e substratos no desenvolvimento de mudas de maracujazeiroamarelo em Aquidauana-MS. Revista Brasileira de Fruticultura, Jaboticabal-SP, v. 31, n. 1, p. 236-244, 2009.

COSTA, E.; SANTOS, L. C. R.; CARVALHO, C.; LEAL, P. A. M.; GOMES, V. A. Volumes de substratos comerciais, solo e composto orgânico afetando a formação de mudas de maracujazeiro-amarelo em diferentes ambientes de cultivo. Revista Ceres, Viçosa-MG, v. 58, n. 2, p. 216-222, 2011.

COSTA, G. F.; MARENCO, R. A. Fotossíntese, condutância estomática e potencial hídrico foliar em árvores jovens de andiroba (Carapa guianensis). Acta Amazônica, ManausAM, v. 37, n.2, p. 229-234, 2007.

DIAS, T. J.; CAVALCANTE, L. F.; PEREIRA, W. E.; FREIRE, J. L. O.; SOUTO, A. G. L. Irrigação com água salina em solo com biofertilizante bovino no crescimento do maracujazeiro amarelo. Semina: Ciências Agrárias, Londrina-PR, v. 34, n. 4, p. 1639-1652, 2013.

FERREIRA, D. F. SISVAR - Sistema de análise de variância. Versão 5.3. Lavras-MG: UFLA, 2010.

FEY, R.; ZOZ, T.; STEINER, F.; CASTAGNARA, D. D.; FERREIRA, G. Crescimento inicial de mudas de maracujazeiro amarelo em função de doses crescentes de superfosfato simples. Agrária: Revista Brasileira de Ciências Agrárias. Recife-PE, v.5, n.3, p.347-353, 2010.

IBGE. INSTITUTO BRASILEIRO DE GEOGRAFIA E ESTATÍSTICA. Produção Agrícola Municipal. Rio de Janeiro-RJ: IBGE, 2013.

MAGUIRE, J. D. Speed of germination aid in selection and evaluation of seedling emergence and vigor. Crop Science, Madison-USA, v. 2, n. 2, p. 176-177, 1962.

MARCOS FILHO, J. Fisiologia de sementes de plantas cultivadas. Piracicaba-SP: FEALQ, 2015. 655 p.

MELETTI, L. M. M. Avanços na cultura do maracujá no Brasil. Revista Brasileira de Fruticultura, Jaboticabal-SP, v. 33, n.espec., p. 83-91, 2011.

MENDONCA, V.; RAMOS, J. D.; RUFINI, J. C. M.; PIO, R.; CARRIJO, E. P.; GONTIJO, T. C. A. Diferentes substratos e ambientes na formação de mudas de maracujazeiro-amarelo. Revista Científica Rural, Bagé-RS, v. 10, n. 2, p. 10-15, 2005.

MORGADO, M. A. D.; FIALHO, G. S.; BRUCKNER, C. H.; MELO, L. A. Non-destructive estimation of chlorophyll content in yellow passion fruit leaves. Revista Brasileira de Agropecuária Sustentável, Viçosa-MG, v. 1, n. 1, p. 74-78, 2011.

PRADO, R. M.; VALE, D. V.; ROMUALDO, L. M. Fósforo na nutrição e produção de mudas de maracujazeiro. Acta Scientiarum Agronomy, Maringá-PR, v. 27, n. 3, p. 493-498, 2005.

PORTO, J. S.; AMORIM, Y. F.; REBOUÇAS, T. N. H.; LEMOS, O. L.; LUZ, J. M. Q.; COSTA, R. Q. Índice SPAD e crescimento do tomateiro em função de diferentes fontes e doses de nitrogênio. Scientia Plena, Aracaju-SE, v. 10, n. 11, p. $1-8,2014$ 
SÁ, F. V. S.; BERTINO, A. M. P.; FERREIRA, N. M.; BERTINO, A. M. P.; SOARES, L. S.; MESQUITA, E. F. Formação de mudas de maracujazeiro amarelo com diferentes doses de esterco caprino e volumes do substrato. Magistra, Cruz das Almas-BA, v. 26, n. 4, p. 486- 494, 2014.
ZANELLA, F.; SONCELA, R.; LIMA, A. L. S. Formação de mudas de maracujazeiro "amarelo" sob níveis de sombreamento em Ji-Paraná/RO. Ciência e Agrotecnologia, Lavras-MG, v. 30, n. 5, p. 880-884, 2006. 